\title{
The System Analysis in Language Teaching and Learning for Technical Students in Russia
}

\author{
http://dx.doi.org/10.3991/ijet.v10i5.4740 \\ Tatiana V. Sidorenko and Vladimir Z. Yampolsky \\ National Research Tomsk Polytechnic University, Tomsk, Russian Federation
}

\begin{abstract}
Integration of the Russian system of engineering education into the global educational domain compelled Russian universities to enhance the importance of humanities in engineering programs with a special focus on foreign languages. However, it must be admitted that the system of language training in Russia at a university level comes up against serious problems of historical, economic or political backgrounds, for which reason there are processes in the system that hamper a solution of the tasks set before the university and the society. The solution requires strong and decisive initiatives capable to improve the situation with the language proficiency among the graduators. Therefore, there is a rapid need in essentially new approaches to teaching foreign languages attain the desired outcomes for engineers, which reflect not only subject-oriented knowledge but also personal skills and the ability to effectively communicate with an opponent or a partner. The need to identify barriers towards high-quality language courses at a university level motivated the authors to carry out a special research based on the methods that are typical to system analysis.
\end{abstract}

Index Terms - efficiency criteria of language training, interdisciplinarity, principles to design language training, system analysis in projecting language courses.

\section{INTRODUCTION}

The recent intensive development on the intellectual labor market and globalization of the engineering society has led to the significant changes in the Russian educational standards over the last decade. This governmental attempt is aimed at reformation of the national system of higher professional education in view of the newlydefined desired attributes of engineers.

The national legislation obliges the Russian universities to modify their programs in compliance with the new standards. Along with the natural ambition of the higher educational institutions to graduate globally competitive specialists, the Law on Education in the Russian Federation additionally promotes the rapid needs in substantially new approaches to training engineers [1].

The new vision of engineering education is to ensure the learning where students can attain the expected outcomes, which reflect not only the subject-oriented knowledge but also the personal skills and ability to effectively communicate with an opponent, a customer or a partner.

In this endeavor the importance of the systematic inclusion of foreign languages into the engineering programs in Russian universities rises to the top of the list as English is consistently replacing all other languages on the globe and becomes an international language.
The current situation with the language proficiency is far from the desired that can be explained by a number of reasons, mostly historical. Although understanding of the problem origin does not solve this problem itself. The solution requires strong and decisive actions, initiatives capable to improve the situation with the language proficiency among the graduators. In the framework of this research we make an attempt to identify "the weaknesses" of the current system and propose some measures to eliminate them. For the purpose of discussion, we believe that it does make sense to represent the university language training as an entire system with its properties and processes, structure and its components in the form of a model.

\section{LANGUAGE TEACHING AND LEARNING In A}

\section{TECHNICAL UNIVERSITY AS AN EDUCATIONAL SYSTEM}

In order to manage any process or system, one has to envision clearly the subject to management. It is impossible to control that is not distinctly outlined and cannot be described and presented as a model. The model is assumed to be the description of the functioning and development objectives of some system in a formalized language [2]. In conformity with the system analysis, the system of language education in a technical university possesses inputs, processes and outputs. It receives the stimuli, information, resources and while in operation transforms them into services, products, results. The maximum effect of the system performance is achieved in the context of the optimal regulating of the functions of its components for the end of purpose. Clear understanding of the purpose is of primal importance. However, when constructing a model of any educational system it is the stage whereat the first difficulty comes up.

Pursuant to the regulatory documents, the purpose of language training in a technical university is defined as the formation of the graduates' commitment to act as the entities in the international professional community [3]. However, the commitment cannot be single valued as the human height, for example, since this is quite an abstract concept. Therefore, such objective is subject to decomposition, which implies its rearranging into independent subgoals and objectives expressed most often in terms of the expectation. In our case, the learning results, which are presented in the syllabus of any academic discipline, can be considered as the expected outcomes of the system functioning. The learning outcomes in the syllabus "Foreign language" are expressed in terms of the following skills:

- Find, extract, analyze, interpret, and represent significant professional information in a foreign language in oral or written form; 
- Master spoken language to be able to handle social and communicative tasks in typical situations of professional field and academic environment as well as to present research findings and take part in scientific conferences in a foreign language;

- Master written language to be able to present research findings and write research papers, theses, abstracts, and synopses in a foreign language;

- Cooperate with representatives of different cultures in carrying out professional activities in a foreign language, be able to understand and overcome crosscultural differences, be tolerant and take responsibility to support and develop partnership and trustful relationship;

- Use foreign language knowledge to plan and implement strategic directions of intellectual, cultural, moral, and professional self-development, selfeducation and self-improvement;

- Work in a team to perform projects in a foreign language and demonstrate willingness to cooperate with other team members [4].

Furthermore, if we are referring to establishment and management of a certain bigger system, we believe it necessary to elaborate what these terms mean. The management, as is known, is realized using the information processes carried out in any system, and aimed at developing solutions that contribute to the end of purpose. The administrative objectives consist in the effective use of the labor and material and technical resources for achievement of the targeted and/or possible result. The management is designed to solve two major tasks:

- to support the system functioning;

- to ensure the system development by improving the methods and approaches, implementing the technological and technical innovations [5].

The management model can change in the course of functioning due to the changes in the ambient medium having an impact on the system targets as a whole. Thus, the model, representing the administrative processes, appears to be some domain in which different management actions are played through for the selection of optimal solutions, and in this case, for the process to improvement of the foreign language teaching and learning.

Establishing of the language training is understood as the whole of processes by which the teaching and learning activities are divided into separate tasks, and then the implementation of these tasks is ensured through the coordination of certain actions.

\section{LAnguage Training Model In A TeChnical UNIVERSITY}

The teaching and learning process, when considered as a system, consists of a number of structural levels and their element, as well as specific synergies between all elements of the system. The following structural levels can be identified in the analyzed system:

a) the target level, indicating the content of the objectives and principles, that to be the basis of the process;

b) the methodological level, allowing identification of the didactic tools set; c) the content-related level, describing the competences and stages of their formation;

d) the structurally technological level, describing the organizational principles and technological characteristics of the process.

Let us call the demand of the intellectual labor-market and the requirements framed at the level of the Ministry of Education as the "inputs" of the model and define the training philosophy, which is laid down as underlying in a new system. The following is considered as the principles of the teaching philosophy: continuity, flexibility, adaptability, professional focus, focus on innovation, focus on metasubject in learning technologies and materials. And let us give reasons for our preference.

The principle of continuity is caused by necessity of reestablishment of communications between the school and the university in terms of language training that is mainly due to the development and execution of the standard procedure defining the requirements and norms. The current schooling system is not ready to provide the students in full measure with the adequate level of the foreign language fluency that allow matching "the entrant requirements" of the university programs. "The entrant requirements" meet the level which is not below B1 [6]. As a result, in real terms, these requirements are not met, and the universities have to bridge the gap in knowledge of the school leavers with that was not taught within a framework of the school curricula.

The flexibility principle is accounted for the need for creation of more flexible mechanisms of the system operation that results in a fast update of the educational material and its actualization. The flexibility implies the modularity and, as a consequence, the variation. Herewith the training course is divided into blocks/modules, which in their turn can be easily joined up with one another, as well as be modified on the format, content and scope.

The principle of adaptability enables the system to reduce the sensitivity to the changes occurring both inside and outside. Mechanisms for collaboration of the components within the system are to be configured so that any internal or external influence could not make the system loose its functional and target focus.

The professional focus of the teaching and learning activities implies the consideration of the professional needs of the target group of students, but not by means of the educational material with the professional content in the form of lexical stuffing, while through creation of the definite formats and conditions that make it possible to generate and develop the competences with the students, which would enable them to perform the professional tasks.

Metasubject in learning is expressed by the availability of the extended knowledge due to integration of the knowledge domains. Focus on an innovation is mainly based on the system's ability to take on the new technologies and teaching approaches there based on.

The success of the system performance depends on the available necessary conditions. In this case, these conditions are:

- motivation of the students in study of the discipline;

- professional competence of the professors;

- engineering and methodological infrastructure of the educational process. 
PAPER

The System ANALysis In LANGUAGE TEACHING AND LEARNING FOR TECHNICAL STUdENTS IN RUSSIA

\section{The Methodological LeVel Of The LANGUAGE TRAINING MODEL}

As known, the objective is achieved by means of the selected tools and approaches. In reference to technical universities, it is interdisciplinary and competence-based approaches. The competence-based approach of the graduates' training model is focused on the formation of the capacities responsible for the creativity, independence, responsibility, competitiveness, pursuance of selfdevelopment [6]. With regard to the language training, the competence-based approach came out in accentuation of the academic skills.

The academic skills are understood as activities that the students require in process of training (academic writing, academic reading, preparation and making presentations, lecturing, etc.) while being common, i.e. of general disciplinary nature. The skills can be formed in the framework of a separate course, in process of the students' independent work or can be integrated into one or more disciplines (including the language ones) as a component, which is acquired concurrently with the other competencies and knowledge. The shift towards the acquisition of academic skills has become the primary reason for the actualization of the modular training.

The formation of the assumed competences necessitated the teachers to make the language teaching and learning process more integrated, professionally-focused and multi-disciplinary. At that it is important to present the foreign language not only as an object of study, but also as a means of formation of the subject specific competences [7]. The interdisciplinarity reflects the integrative nature of the current scientific knowledge as a process of interscientific fusion and integration of sciences.

The introduction of interdisciplinarity is based on the methodology of a learner-centered approach subject to the competency-based model of a graduate. This approach of the humanities teaching implies the trinity "discipline profession - person". In this approach the underlying logic of teaching lies not only in that to give the students an idea about the subject, but also to discover the metasubject of the subject scope, to show how important the skills formed on the basis thereof for their future profession, to teach how to apply knowledge in the solution of the specific professional tasks [8]. The above makes it possible to specify the teaching and learning tools set in the form of teaching methods and types of learning activity. These methods and activity types include: research, domainspecific learning, project-based learning, and case technology.

According to the purpose of training its content should be focused not on a narrow-subject area of the learners, but on the formation of the skills that enable the person to develop in this subject area. Based thereon, the content should be considered as three components: social- business, metasubject and academic.

The social-business component is realized within the level of language proficiency from A2 to B1 while being responsible for the formation of the skills which are necessary to the students for social integration into the foreign environment. The content of the first component can be divided into such communication needs as: "I am a person", "I am Society". As a rule, they are represented by frequency themes that contain certain verbal communicative situations (introduction, description of the location, description of the problem (health), the place of study, leisure, travel, etc.). The knowledge of the business communication is defined by the general qualification requirements of all areas of the engineering training and expressed through such needs as:

a) to self-present at a job placement interview;

b) to present own company to the business-partner;

c) to establish business partnerships with different cultures and so forth [8].

The next component of the content level is a metasubject unit being responsible for the formation of the skills related to the successful professional career. The main emphasis is made here on the foreign communication (both written and verbal), which is realized in the professional context. The professional aspect of this training stage is characterized by the staged formation of the personal attitude to the future careers and implemented through the mastery of a range of general engineering concepts such as the problem identification, description of the process, design, planning, project management, innovation and so on. In other words this means the ability of the students to integrate their language experience into a professional environment during communication on the general professional level with the progressive integration into the area of expertise. The purpose of this stage is to "bring" the training to the level of personal and professional values that implies the formation of the professional competence as a personality measure and the possibility of self-fulfillment in life and society.

The academic skills aimed at the highest stage of the university training are formed during the Master degree stage. This stage is final and very important to understand the importance of communication as a means of acquiring the new knowledge and own perception as the subject of the professionally-language environment. The training content assumes the study of the terminological system, the communication technologies, a role of communication in the society, the forms of scientific communication, critical analysis of the results.

Thus, the content of the language training in the technical university should be presented as a system of integration of the social, business, professional and linguistic knowledge and skills which are acquired in process of the mastery of the subject and language components, based on the intersubjective interaction within the situations of the social, business, academic and professional communication. At that it is very important to create the conditions in which through the system of training tasks there formed a system of competences, expressed in terms of the students' willingness to absorb the knowledge of social realm, to apply the obtained knowledge and subjective analysis of their communicative potential [9].

Every system has its own organizational peculiarities, which are based on the specific attributes of the system. In our case we have the following attributes: modularity, interdisciplinary, independence, local control, linguistic authenticity, networking. Let us consider these attributes of the system in detail, see Table I.

The listed attributes of the system can be easily implemented, although they are time-consuming as regards development and testing of the educational and logistical resources and gaining teaching experience. Based thereon, the model of the language training establishing and management in a technical university can be presented as follows (Fig. 1). 
PAPER

The System ANALYSiS In LANGUAGE TEACHING AND LEARNING FOR TECHNICAL STUdENTS IN RUSSIA

TABLE I.

The Attributes Of The System On Establishment Of The Teaching Process

\begin{tabular}{|l|l|}
\hline \multicolumn{1}{|c|}{ Attributes of the system } & \multicolumn{1}{c|}{ Purpose/function } \\
\hline Modularity & $\begin{array}{l}\text { Designed to eliminate such problem as mismatch of the syllabus and the needs of the target group and changea- } \\
\text { bility of the management policy by priorities at the university level. }\end{array}$ \\
\hline Interdisciplinarity & Provides integration of the knowledge-engineering; formation of more flexible learning model. \\
\hline Independence & Caused by the urgency of integration practices for introduction of the research activities and projects. \\
\hline Local control & Allows fast changes in the situation when the system fails or ceases to function in the set mode. \\
\hline Linguistic authenticity & $\begin{array}{l}\text { Ensures the involvement of the native speakers in the educational process, to simulate an adequate linguistic } \\
\text { and cultural environment. }\end{array}$ \\
\hline Networking & Increases the possibility of independent work of the students. \\
\hline
\end{tabular}

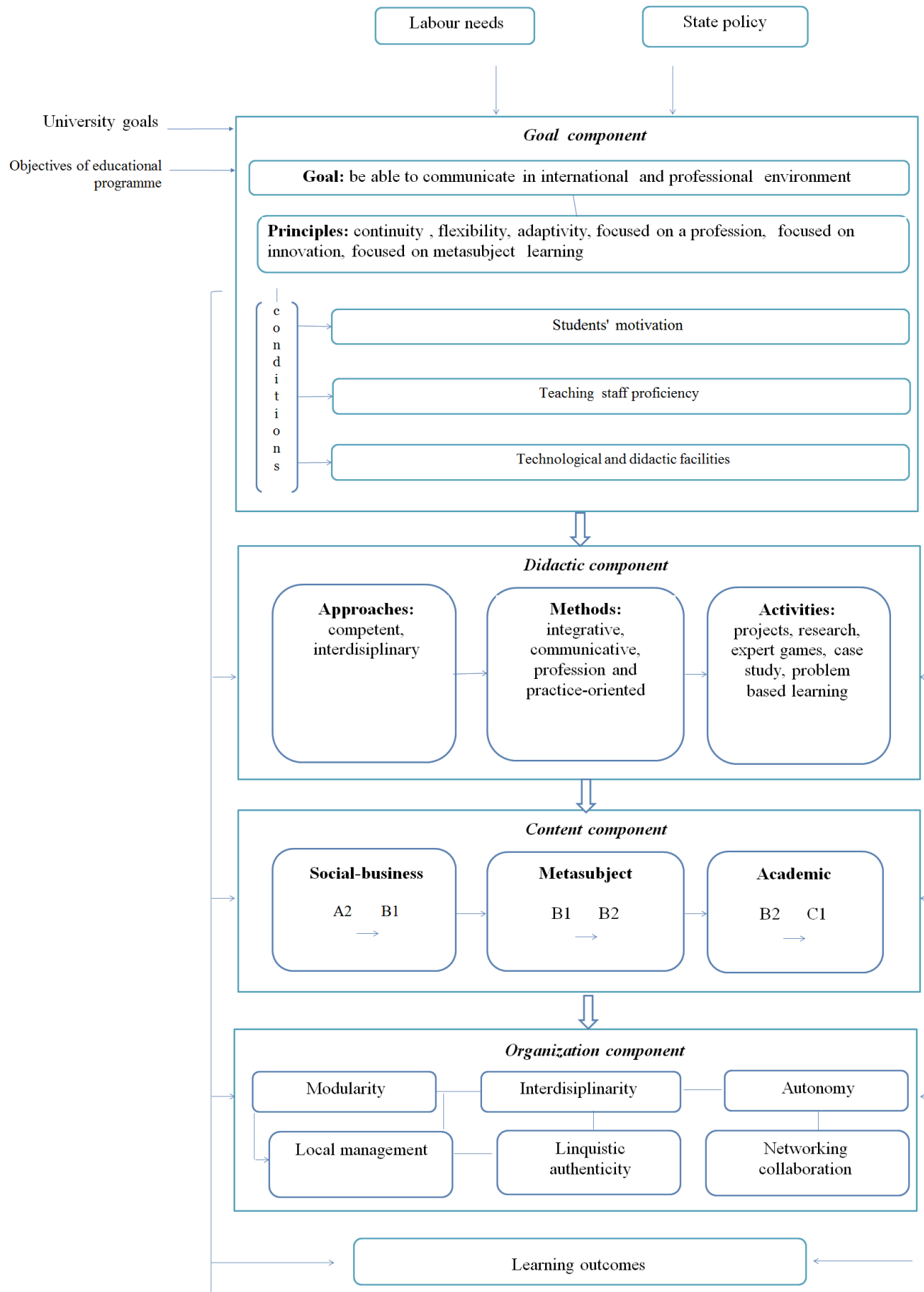

Figure 1. Language training model in a technical university 


\section{EFFICIENCY CRITERIA OF THE LANGUAGE TRAINING MODEL}

The process of the criteria specification, as well as the process of the objectives setting is to a great extent a creative process that in each specific case requires a tailored solution and consideration of the specific character of the system under study and its functioning environment. Thus, the criteria should represent the most effective performance evaluation of the system functioning, as well as the evaluation of all processes within the system to obtain the targeted results.

The major task at this stage of the study was formation of the performance criteria of the language training in a technical university for the purpose of verification of the suggested model of organization and management of the language education in a technical university for further specification of the actions to achieve the objectives with the lowest possible side effects and maximum expected outcomes and without apparent increase in quantity of the used resources.

For a start, let us specify the efficiency factors of any system performance. According to Milner B. Z. et al. we consider the following efficiency factors:

- the strategic management objectives;

- the sustainability of the management processes structure;

- the system capability;

- the quality of the organizational behavior [10].

These underlying factors make it possible to establish a system of criteria presented in Table II. As applied to the experimental system, we will take the liberty to slightly modify the wording proposed by the authors, with a view to their customization to the issues under investigation. Here is some explanation to Table II.

It is known that the concept of efficiency is closely associated with such notion as performance. Common to them is their relativity, i.e. that the performance indicators can be measured only as compared to the basis or reference (in this case, evaluation criteria of the foreign language proficiency level, such as A2, B1, C1 are taken as a benchmark). The differences lie in the fact that the performance is defined by the achieved result irrespective of the resources spent therefor, and the efficiency is the ratio of the obtained results and the expenditures connected with their achievement.

The Diversity Law by Ashby says: successful functioning of the system is based on the achievement of such di-

TABLE II.

PERFORMANCE CRITERIA AND FACTORS

\begin{tabular}{|l|l|}
\hline \multicolumn{1}{|c|}{ Efficiency factor } & \multicolumn{1}{c|}{ Performance criteria } \\
\hline $\begin{array}{l}\text { The strategic manage- } \\
\text { ment objectives }\end{array}$ & $\begin{array}{l}\text { Performance is the extent to which the } \\
\text { intended target is gained }\end{array}$ \\
\hline $\begin{array}{l}\text { The sustainability of the } \\
\text { management processes } \\
\text { structure }\end{array}$ & $\begin{array}{l}\text { Efficiency is the balance of processes and } \\
\text { resources, excess of the growth of resource } \\
\text { efficiency over expenses }\end{array}$ \\
\hline The system capability & $\begin{array}{l}\text { Stability is the ability to respond to the } \\
\text { management decisions; stable performance; } \\
\text { competitiveness }\end{array}$ \\
\hline $\begin{array}{l}\text { The quality of the organi- } \\
\text { zational behavior }\end{array}$ & $\begin{array}{l}\text { Information security is the availability and } \\
\text { performance of the data exchange systems } \\
\text { at the level of management and training }\end{array}$ \\
\hline
\end{tabular}

versity, which ensures the internal stability of the managerial system and stability of its interaction with the external environment [11]. The rationally organized system ensures the steady communication of all elements. The basic characteristics of the managerial processes rationality can be:

- the number of the management levels and the synergies between the hierarchy links;

- operational efficiency and quality of the solutions;

- low labor intensity and efficiency;

- resource efficiency.

Another important factor is the system capability. Under that logic is the better capability of the system, the higher its managerial efficiency. The focus on innovation determines the level of renewal of the structural components of the teaching and learning process which are able to affect the growth of competitiveness of the educational program for achievement of the expected outcomes. The managerial adaptability is a response to the rapidly changing challenges of the external and internal environment. At that the adaptability is fairly abstract concept with no specific values of measurement. If the system is highly flexible and meets the conditions of the intellectual labormarket while considering the risks related to the changes of the external environment, it is defined as highly adaptive.

An important factor of the management performance evaluation is the quality of the organizational behavior, evaluated by the criteria of the cost effectiveness and information security. The concept of cost effectiveness involves minimizing the cost of resources, not to the detriment of performance and managerial efficiency. The information security implies the availability of the transmission medium for the big data, access-to-information, stable functioning and high capacity.

Based on the above, let us define the performance criteria for the experimental system of the language education in a technical university. They can be the following:

Criterion 1. Matching of the teaching and learning content and methods and the tasks and objectives of the principal educational program, the demands of the intellectual labor-market, strategic goals of the university development (professional focus).

Criterion 2. Integration of the language education into the complex system of the specialists' training (professional focus).

Criterion 3. Mobility of the processes of the language training system (electiveness, modularity, fast update of the teaching and learning resource base).

Criterion 4. Staffing mobility and high degree of focus on innovation (linguistic authenticity, networking).

Criterion 5. Engineering and technical availability of the language education system for realization of the efficient information support for the teaching and learning activities (independence, networking, local control).

Criterion 6. Cost reduction for establishing and realization of the foreign language teaching and learning due to the effective management of the resources.

To understand better the bottom line of every presented criterion, let us set the local criteria defining the processes leading to the end of purpose, see tables III and III.I. 
TABLE III.

LOCAl CRITERIA (\# 1-3) THE EFFECTIVENEss OF THE LANGUAGE TRAINING IN A TECHNICAL UNIVERSiTy

\begin{tabular}{|l|l|l|}
\hline \multicolumn{1}{|c|}{ for Criterion 1 } & for Criterion 2 & \multicolumn{1}{c|}{ for Criterion $\mathbf{3}$} \\
\hline $\begin{array}{l}\text { - the pedagogical expert evaluation of the } \\
\text { objectives of the principal educational } \\
\text { program for the specialists' training; } \\
\begin{array}{l}\text { - the didactic tools set to meet the meth- } \\
\text { ods and technologies of the engineering } \\
\text { education. }\end{array}\end{array}$ & $\begin{array}{l}\text { - the interdisciplinary format of the training; } \\
\text { - the integration of humanities knowledge that is } \\
\text { relevant for the engineering specialties. }\end{array}$ & $\begin{array}{l}\text { - a system of regular expert review of the } \\
\text { educational material; } \\
\text { - the technological infrastructure of the train- } \\
\text { ing courses; } \\
\text { - the mechanisms for interchange of the learn- } \\
\text { ing resources; } \\
\text { - the students' involvement in the development } \\
\text { and update of the learning material; } \\
\text { - the variability of the learning material. }\end{array}$ \\
\hline
\end{tabular}

TABLE IV.

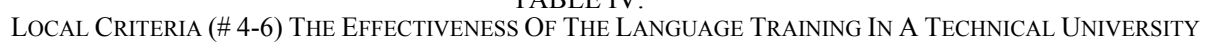

\begin{tabular}{|c|c|c|}
\hline for Criterion 4 & for Criterion 5 & for Criterion 6 \\
\hline $\begin{array}{l}\text { - the system of requirements to the qualifi- } \\
\text { cation of the foreign language teacher to } \\
\text { be eligible for employment in a technical } \\
\text { university; } \\
\text { - the mechanisms for support and devel- } \\
\text { opment of the professional knowledge and } \\
\text { skills of the teachers; } \\
\text { - the feedback between teachers and } \\
\text { students, as well as the administration of } \\
\text { the Institute; } \\
\text { - the involvement of the experts, native } \\
\text { speakers }\end{array}$ & $\begin{array}{l}\text { - the specialized electronic platforms and re- } \\
\text { sources for teaching and learning; } \\
\text { - the system to deliver information among } \\
\text { students and teachers regarding the language } \\
\text { activities; } \\
\text { - the information resources management }\end{array}$ & $\begin{array}{l}\text { - a system of organization and management of } \\
\text { the training on the basis of interchangeable } \\
\text { components / modules; } \\
\text { - the e-learning platforms to post the training } \\
\text { and reference materials; } \\
\text { - the increase of the (controlled) portion of the } \\
\text { students' independent work; } \\
\text { - the increase (encouragement) of the research } \\
\text { activity of the teachers (grants, mobility, } \\
\text { competitions) }\end{array}$ \\
\hline
\end{tabular}

\section{CONCLUSION}

In conclusion, it should be mentioned, that the findings presented in this study are an expert view point of the authors, based on the systematic methods of analysis, as well as on the personal experience both as a teacher of foreign languages, as well as the head of the technical university department. The suggested processes and their characteristics recorded in the form of a model of the language training, proved themselves in practice. So, in 2013 in the framework of the Russian grant there were developed the elective courses aimed at teaching in the individual linguistic, academic and professional aspects, for example, debates, effective presentation, technical translation, basics of academic writing. The courses were organized in a modular format. In 2014, some of the presented courses were implemented on the basis of the electronic educational platform MOODLE that deserved the positive response of the students and significantly expanded the scope of the traditional lessons. The available involvement of the native speakers had a significant effect resulting in elimination of the language barrier and in increase of the self-interest of the students to the study a foreign language (English).

As of today, one can say that the Russian language training has gained considerable background in the form of practical developments, allowing proper coordination of the actions for the further development of the subject under study. In terms of the system standardization it is advisable to present the development of the language training in high school as two interrelated processes: 1) improvement of the current system and 2) creation of new approaches and technologies for its development. The development process, in its turn, should be based on the principle of continuity and the evolution analysis of the prior period and consideration of the positive achievements of the national and oversea scientific theory and practice.
The statistics proves that the language situation in our country is getting better year by year [10], and in order not to miss the emerging trend, it is necessary to maximize the attention to the solution of this problem right at the level of the higher education. The improvement of the language training for technical university students should be considered at the up-to-date level of development of the language and engineering education as one of the major components of the universities' internationalization, since the knowledge of the foreign language means a new stage in the professional socialization of the engineer and pluralization of the engineering profession [11].

\section{REFERENCES}

[1] A. S. Kravchenko Organizational model of the company management. The essays of the management specialist [electronic resource]. Mode of access: http://www.vodaspb.ru/arhive/ dr_autor/model_org_upr_komp/model_org_upr_komp.pdf (access on: 07.01.2015). (rus)

[2] T. G. Agiievich, T. A. Daeva The special aspect of the performance criteria selection of the management systems. Multidisciplinary journal of the scientific publications "Discussion". Section: Economics. 2014. No. 4 (45) [electronic resource]. Mode of access: http://www.journal-discussion.ru/publication.php?id=1077 (access on: 07.01.2015). (rus)

[3] The draft program for teaching the foreign languages (English, German, French, Spanish) for the students of non-language high schools and departments / developed under guidance and the general editorship of Ter-Minasova S. G. M., 2009. Pp. 24. (rus)

[4] The standard syllabus of the unified module of the discipline "Foreign Language for the Professional purposes" [electronic resource]. Mode of access: http://portal.tpu.ru:7777/departments/ kafedra/iyaik/study\%20organization/ (access on: 28.04.2014). (rus)

[5] Common European Framework of Reference for Languages: learning, teaching, assessment. Moscow State Linguistic University. Available at: http://www.linguanet.ru/ (access on: 25.01.2015) (rus).

[6] V.A. Kozyrev et al. Competency-based approach in teacher training [text]. SPb.: Publisher Gerzen A. I. RSPU, 2004. Pp. 392. (rus) 
[7] T. V. Sidorenko, S. V. Rybushkina Debate as a means of formation of the metasubject competencies in foreign language training with the students of a technical university // Bulletin of Novosibirsk State Pedagogical University. 2014. No. 6. Pp. 7-21. DOI: http://dx.doi.org/10.15293/2226-3365.1406.01

[8] T. I. Suslova Report on the scientific and methodological work for 2014. Interdisciplinary approaches in teaching of the humanities in the university: the main trends, challenges, goals and objectives. Department of Philosophy and Sociology of Tomsk State University. 2014. Pp. 23. (rus)

[9] T. V Sidorenko, Y. V. Falkovich The content and organization of the language training in the non-linguistic universities // Bulletin of Surgut State Pedagogical University. 2013. No. 5 (26). Pp. 190195. (rus)

[10] Russia surpassed Italy and France in the world ranking of English fluency "Index EF2013». [Electronic resource]. URL: http://www.ef-rus-sia.ru/about-ef/press/release/russia-ahead-ofitaly-france-ef-epi/ (rus)

[11] E. B. Oleynicheva Foreign language as an indicator of the students' differentiation in the Russian technical universities: the thesis research ... PhD in sociology: 22.00.04. - Novocherkask, 2003. Pp.155 (rus)

\section{AUTHORS}

T. V. Sidorenko is with the Institute of Cybernetics, National Research Tomsk Polytechnic University, 84/3 Str. Sovetskaya, Tomsk, Russian Federation (e-mail: sidorenkot@,tpu.ru). T. V. Sidorenko is the Head of Foreign languages Department, Ph.D

V. Z. Yampolsky is with the Institute of Cybernetics, National Research Tomsk Polytechnic University, 84/3 Str. Sovetskaya, Tomsk, Russian Federation (e-mail: yampolsky@incom.ru). V. Z. Yampolsky is a Chief research scientist, Doctor in Technical Sciences.

Submitted, 21 May 2015. Published as resubmitted by the authors on 08 June 2015. 